\title{
Qualidade de vida: abordagens, conceitos e avaliação
}

CDD. 20.ed. 613.7

\author{
Érico Felden PEREIRA* \\ Clarissa Stefani TEIXEIRA** \\ Anderlei dos SANTOS ${ }^{* * *}$ \\ *Universidade do Esta- \\ do de Santa Catarina. \\ **Sociedade Educacio- \\ nal de Santa Catarina \\ ***Pontifícia Univer- \\ sidade Católica do \\ Paraná
}

\section{Resumo}

Apesar da grande relevância social, o tema qualidade de vida apresenta imprecisões teórico/metodológicas o que dificulta a investigação, o diálogo entre as diferentes áreas que trabalham com o tema e, principalmente, a aplicação do conhecimento produzido na melhoria da qualidade de vida da população. Buscando contribuir para a clarificação do conceito este estudo teve como objetivo, a partir da leitura, discussão e análise da literatura especializada, apresentar as principais abordagens, conceitos e propostas de classificação e avaliação da qualidade de vida. Verificou-se que as abordagens e conceitualizações sobre a qualidade de vida se apresentam na literatura de forma diversificada, e, por vezes, divergentes. A falta de consenso teórico leva muitas pesquisas a utilizarem conceitos como saúde, bem estar e estilo de vida como sinônimos de qualidade de vida. Novas abordagens epistemológicas no estudo do tema são necessárias bem como estudos que analisem a qualidade de vida em situações de intervenção.

UnIteRMOS: Qualidade de vida; Formação de conceito; Classificação.

\section{Qualidade de vida}

A crescente preocupação com questôes relacionadas à qualidade de vida vem de um movimento dentro das ciências humanas e biológicas no sentido de valorizar parâmetros mais amplos que o controle de sintomas, a diminuição da mortalidade ou o aumento da expectativa de vida. Assim, qualidade de vida é abordada, por muitos autores, como sinônimo de saúde, e por outros como um conceito mais abrangente, em que as condiçóes de saúde seriam um dos aspectos a serem considerados (FLECK, Louzada, Xavier, Chachamovich, Vieira, Santos \& Pinzon, 1999).

Devido à sua complexidade e utilização por diversas áreas de estudo, conforme aborda FARQUHAR (1995), a falta de consenso conceitual é marcante. Suas definições na literatura especializada apresentam-se, tanto de forma global, enfatizando a satisfação geral com a vida, como dividida em componentes, que, em conjunto, indicariam uma aproximação do conceito geral. A forma como é abordada e os indicadores adotados estão diretamente ligados aos interesses científicos e políticos de cada estudo e área de investigação, bem como das possibilidades de operacionalização e avaliação.
Dependendo da área de interesse o conceito, muitas vezes, é adotado como sinônimo de saúde (Michalos, Zumbo \& Hubley, 2000; Schmidt, Power, Bullinger \& Nosikov, 2005), felicidade e satisfação pessoal (RENWICK \& BROWN, 1996), condiçõos de vida (Buss, 2000), estilo de vida (NAHAS, 2003), dentre outros; e seus indicadores vão desde a renda até a satisfação com determinados aspectos da vida. Devido a essa complexidade, conforme abordam Dantas, SaWada e Malerbo (2003) e Seild e ZANONn (2004) a qualidade de vida apresenta-se como uma temática de difícil compreensão e necessita de certas delimitações que possibilitem sua operacionalização em análises científicas.

É considerada como a percepção do indivíduo de sua posição na vida no contexto da cultura e sistema de valores nos quais vive e em relação aos seus objetivos, expectativas, padrōes e preocupações (WHOQOL, 1994) e mesmo como uma questão ética (SANTIN, 2002), que deve, primordialmente, ser analisada a partir da percepção individual de cada um (GILl \& FEISNTEIN, 1994). Recorrendo-se à etimologia do termo qualidade, ele deriva de "qualis" [latim] que significa o modo de ser característico de alguma coisa, 
tanto considerado em si mesmo, como relacionado a outro grupo, podendo, assim, assumir tanto características positivas como negativas. Porém, quando se fala em qualidade de vida, acredita-se que, geralmente, refere-se a algo bom, digno e positivo (SANTIN, 2002).

Os estudiosos do tema têm buscado e sugerido diferentes metodologias para o tratamento científico de um conceito tão complexo e que tem a subjetividade como característica importante. O estudo do tema conforme aborda TANI (2002), está marcado pelo fato de diversas áreas, dentro das possibilidades de cada uma, tentarem contribuir para a clarificação do conceito. No entanto, é importante salientar que muitos estudos se limitam exclusivamente a descrição de indicadores sem fazer relaçôes diretas com a qualidade de vida, ou seja, tomam características como escolaridade, ausência dos sintomas das doenças, condiçôes de moradia unicamente como indicadores de qualidade de vida sem investigar o objetivo disso para as pessoas envolvidas. Se, de um lado isso contribui para as possibilidades de investigaçōes em grandes grupos, deixa de considerar a subjetividade particular de cada ser humano na questão de poder avaliar o quão boa é sua própria vida.

\section{Principais abordagens}

DAY e JANKEY (1996) classificam os estudos sobre qualidade de vida de acordo com quatro abordagens gerais: econômica, psicológica, biomédica e geral ou holística.

A abordagem socioeconômica tem os indicadores sociais como principal elemento. O termo qualidade de vida, neste contexto, se popularizou por volta de 1960 quando políticos norte-americanos o usaram como plataforma política. Falar de qualidade de vida naquele momento seria como uma recomendação para o sucesso administrativo. Há registros de que o presidente dos Estados Unidos, Lyndon Johnson, utilizou-se do termo em um discurso em 1964 na Universidade de Michigan que abordava o interesse das pessoas por uma "vida boa" ou "vida de qualidade". Além disso, os discursos da época abordavam o compromisso da sociedade em assegurar às pessoas, estruturas sociais mínimas que lhes permitissem perseguir sua felicidade (DAY \& JANKEY, 1996).

Muitos outros políticos desde então, em diversos países, têm utilizado o conceito de qualidade de vida em suas campanhas e isso, de certa forma, incentivou a pesquisa sobre o tema. Considerando a pesquisa sobre qualidade de vida, especialmente nos Estados Unidos, num primeiro momento os indicadores econômicos foram o parâmetro primordial para se avaliar a qualidade de vida, em um segundo, foram analisados junto aos indicadores sociais. Isso se deve, em parte, ao fato de que com uma ascensão econômica do país, problemas como violência e criminalidade emergiram apesar da riqueza econômica. Assim, os pesquisadores passaram a considerar indicadores sociais como críticos para definir o bem estar da nação. No entanto, as informaçôes de cunho social, coletadas nessa época, se focalizavam apenas em fatores externos, presumidamente determinantes da qualidade de vida, como instrução, renda e moradia (DAY \& JANKEY, 1996), como utilizados, ainda hoje, em larga escala.

A abordagem psicológica busca indicadores que tratam das reações subjetivas de um indivíduo às suas vivências, dependendo assim, primeiramente da experiência direta da pessoa cuja qualidade de vida está sendo avaliada e indica como os povos percebem suas próprias vidas, felicidade, satisfação. O fato das abordagens psicológicas considerarem qualidade de vida, somente enquanto um aspecto subjetivo à pessoa, desconsiderando o contexto ambiental em que está inserida, é a principal limitação dessa linha de pensamento (DAY \& JANKEY, 1996).

De acordo com DAY e JANKEY (1996), para os pesquisadores da abordagem psicológica, os indicadores sociais ou objetivos são limitados e serviriam como indicadores indiretos de qualidade de vida. Qualidade de vida deveria, então, ser analisada considerando a vida atual e um padrão a ser comparado, como proposto por Michalos. Conforme apresentam DAY e JANKEY (2006) esta abordagem combinou múltiplos aspectos de seis dimensões de análise. A primeira refere-se a objetivo-realização e se relaciona às questóes entre o que se tem e o que se quer ter. Um segundo aspecto da teoria analisa o que os povos realmente consideram ser o seu ideal real de vida. Um terceiro tipo envolve a relação percebida entre as circunstâncias atuais e o que se espera se tornar. Um quarto tipo inclui a relação percebida entre qualidade de vida atual e a melhor qualidade de vida que já se teve no passado. Um quinto sugere que uma questão importante a ser analisada é o que é possuído por uma pessoa e pelo grupo de referência e uma sexta considera importante buscar esclarecer o quão bom é o ajuste da pessoa no ambiente em que se está inserido.

As abordagens médicas tratam, principalmente, da questão de oferecer melhorias nas condiçôes de vida dos enfermos (Minayo, Hartz \& Buss, 2000). O termo qualidade de vida, em relação a seu emprego na literatura médica, vem sendo associado a diversos significados, como condições de saúde e funcionamento social. Qualidade de vida relacionada à saúde 
("healthrelated quality of life") e estado subjetivo e saúde ("subjective health status") são conceitos relacionados à avaliação subjetiva do paciente e ao impacto do estado de saúde na capacidade de se viver plenamente (Gill \& Feinstein, 1994).

As teorias médicas de qualidade de vida historicamente têm por base a cura e sobrevivência das pessoas. Também pelo fato que muitas intervençôes médicas causam efeitos colaterais desagradáveis, considerar a qualidade de vida durante o tratamento também é importante. Isto veio como resultado da consciência da comunidade médica de que os tratamentos médicos ou cirúrgicos, embora estendendo a vida, podem reduzir realmente sua qualidade como um resultado de múltiplos ou longos tratamentos e hospitalizações e está de acordo também com um preceito médico segundo o qual os benefícios do tratamento devem ser maiores do que o sofrimento que pode ser envolvido. De um ponto de vista médico, avaliações da qualidade de vida foram usadas para justificar ou refutar tratamentos, no entanto essas avaliaçôes acabaram por mostrar somente o óbvio, por exemplo, o fato de que uma cirurgia do coração pode realçar a qualidade de vida (ou a sobrevida) de pacientes cardíacos (DAY \& JANKEY, 1996).

Embora saúde e qualidade de vida sejam, muitas vezes utilizados como sinônimos, são conceitos que apresentam especificidades, mas também uma grande relação entre si. Existem evidências científicas abundantes, conforme é abordado por Buss (2000), que mostram a contribuição da saúde para a qualidade de vida de indivíduos ou populações, além da contribuição de muitos componentes da vida social para uma boa qualidade de vida e para que se alcance um perfil elevado de saúde. O mesmo autor complementa que é necessário mais do que o acesso a serviços médico-assistenciais de qualidade, é preciso enfrentar os determinantes da saúde em toda a sua amplitude, o que requer políticas públicas coerentes, uma efetiva articulação intersetorial do poder público e a mobilização da população.

As abordagens gerais ou holísticas baseiam-se na premissa segundo a qual o conceito de qualidade de vida é multidimensional, apresenta uma organização complexa e dinâmica dos seus componentes, difere de pessoa para pessoa de acordo com seu ambiente/ contexto e mesmo entre duas pessoas inseridas em um contexto similar. Características como valores, inteligência, interesses são importantes de serem considerados. Além disso, qualidade de vida é um aspecto fundamental para se ter uma boa saúde e não o contrário (RENWICK \& BROWN, 1996).

Em uma tentativa de análise da qualidade de vida de forma mais ampla, saindo principalmente do reducionismo biomédico, Minayo, Hartz e Buss (2000) abordam qualidade de vida como uma representação social criada a partir de parâmetros subjetivos (bem-estar, felicidade, amor, prazer, realização pessoal) e também objetivos, cujas referencias são a satisfação das necessidades básicas e das necessidades criadas pelo grau de desenvolvimento econômico e social de determinada sociedade.

Diferentes aspectos que definem a qualidade de vida são apresentados na literatura, como, por exemplo, poder aproveitar as possibilidades da vida, de escolher, de decidir e ter controle de sua vida (RENWICK \& BROWN, 1996). Cita-se como exemplo o modelo ilustrado na FIGURA 1:

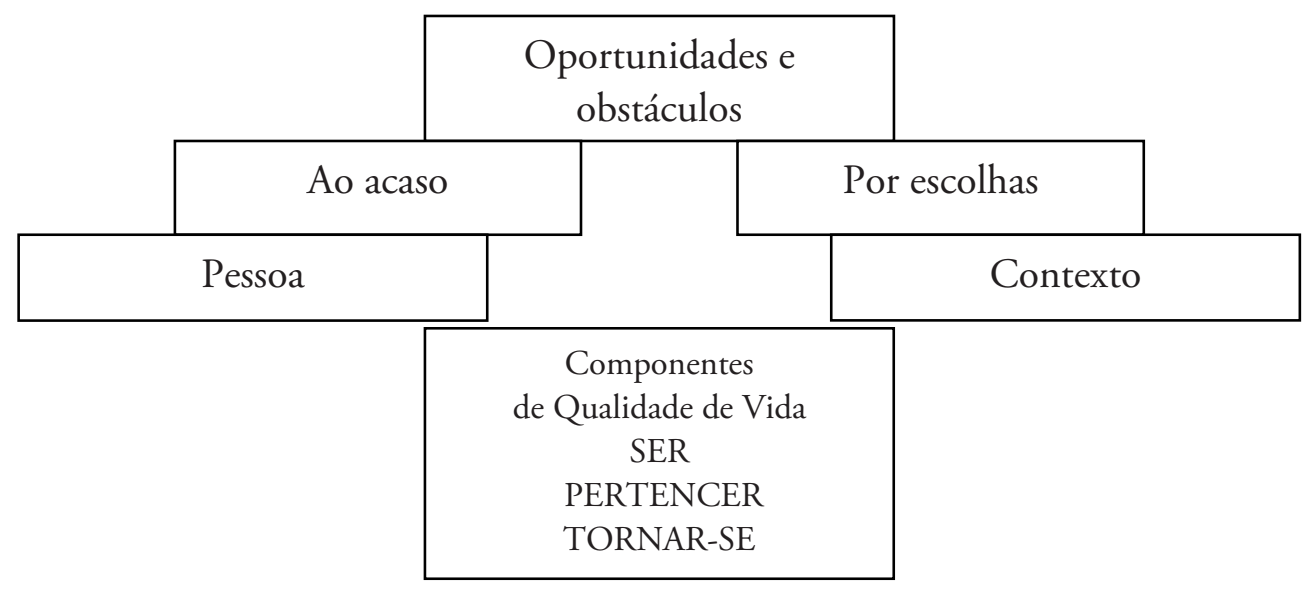

Fonte: adaptado de RemuckeBronn (1996).

FIGURA 1 - Modelo (degraus) para a pessoa aproveitar as possibilidades importantes de sua vida.

Considerando o modelo apresentado, o "ser" é entendido como o que o ser humano é, resultado de sua nutrição, aptidão física, habilidades individuais, inteligência, valores, experiências de vida, etc. Quanto ao "pertencer" trata-se das ligações que a pessoa tem em seu meio, casa, trabalho, comunidade, possibilidade de 
escolha pessoal de privacidade, assim como da participação de grupos, inclusão em programas recreativos, serviços sociais, etc. $\mathrm{O}$ "tornar-se" remete à prática de atividades como trabalho voluntário, programas educacionais, participação em atividades relaxantes, oportunidade de desenvolvimento das habilidades em estudos formais e não formais, dentre outros. Esses componentes apresentam uma organização dinâmica entre si, consideram tanto a pessoa, como o ambiente, assim como as oportunidades e os obstáculos como ilustrado na FIGURA 2.

\begin{tabular}{|c|c|}
\hline $\begin{array}{c}\text { SER } \\
\text { Quem é no campo } \\
\text { individual }\end{array}$ & $\begin{array}{c}\text { FÍSICO } \\
\text { PSICOLÓGICO } \\
\text { ESPIRITUAL }\end{array}$ \\
\hline $\begin{array}{c}\text { PERTENCER } \\
\text { Como a pessoa se } \\
\text { ajusta ao contexto }\end{array}$ & $\begin{array}{c}\text { FÍSICO } \\
\text { SOCIAL } \\
\text { COMUNIDADE }\end{array}$ \\
\hline $\begin{array}{l}\text { TORNAR-SE } \\
\text { O que a pessoa faz } \\
\text { para alcançar suas } \\
\text { expectativas, metas } \\
\text { e aspiraçóes }\end{array}$ & $\begin{array}{c}\text { PRÁTICAS } \\
\text { LAZER } \\
\text { CRESCIMENTO/ } \\
\text { PROGRESSO PESSOAL }\end{array}$ \\
\hline
\end{tabular}

FIGURA 2 - Qualidade de vida: componentes e subcomponentes essenciais.

Apesar da relevância de tal modelo devido sua coerência e abrangência, MinaYo, Hartz e Buss (2000) abordam ainda que a relatividade da noção, que em última instância remete ao plano individual, tem pelo menos três fóruns de referência:

- Histórico: em determinado tempo de seu desenvolvimento econômico, social e tecnológico, uma sociedade específica tem um parâmetro de qualidade de vida diferente da mesma sociedade em outra etapa histórica;

- Cultural: certamente, valores e necessidade são construídos e hierarquizados diferentemente pelos povos, revelando suas tradições;

- Estratificaçóes ou classes sociais: os estudiosos que analisam as sociedades em que as desigualdades e heterogeneidades são muito fortes mostram que os padrões e as concepções de bem-estar são também estratificados: a ideia de qualidade de vida está relacionada ao bem-estar das camadas superiores e à passagem de um limiar a outro.

\section{O conceito}

Apesar de haver inúmeras definições, não existe uma definição de qualidade de vida que seja amplamente aceita. Cada vez mais claro, no entanto, é que não inclui apenas fatores relacionados à saúde, como bem-estar físico, funcional, emocional e mental, mas também outros elementos importantes da vida das pessoas como trabalho, família, amigos, e outras circunstâncias do cotidiano, sempre atentando que a percepção pessoal de quem pretende se investigar é primordial (Gill \& FeIsnTEIn, 1994).

TANi (2002) aborda que, a exemplo da qualidade de vida, determinados aspectos da nossa vida como a felicidade, amor e liberdade, mesmo expressando sentimentos e valores difíceis de serem compreendidos, não se tem dúvida quanto a sua relevância. Trata-se de um conceito para o qual até mesmo uma definição operacional é difícil de ser elaborada. Qualidade de vida, segundo o autor, vem sendo uma ideia largamente difundida na sociedade correndo-se o risco de haver uma banalização do assunto pelo seu uso ambíguo, indiscriminado ou oportunista como acontece, por exemplo, com muitos políticos que prometem elevar a qualidade de vida da população lançando mão de estatísticas muitas vezes irreais para comprovar seus feitos. De um lado se tem a exploração oportunista de um conceito, o que resulta na sua depreciação e, de outro, o reconhecimento de que esse conceito exprime uma meta nobre a ser perseguida, o que resulta na preservação de seu significado e valor.

Atualmente os conceitos mais aceitos de qualidade de vida buscam dar conta de uma multiplicidade de dimensões discutidas nas chamadas abordagens gerais ou holísticas. O principal exemplo que pode ser citado é o conceito preconizado pela Organização Mundial da Saúde (OMS) no qual qualidade de 
vida reflete a percepção dos indivíduos de que suas necessidades estão sendo satisfeitas ou, ainda, que lhes estão sendo negadas oportunidades de alcançar a felicidade e a auto-realização, com independência de seu estado de saúde físico ou das condições sociais e econômicas (OMS, 1998).

Apesar da tentativa de criação de um modelo ampliado de qualidade de vida, Minayo, Hartz e Buss (2000) alertam que:

O relativismo cultural, no entanto, não nos impede de perceber que um modelo hegemônico está a um passo de adquirir significado planetário. É o preconizado pelo mundo ocidental, urbanizado, rico, polarizado por um certo número de valores, que poderiam ser assim resumidos: conforto, prazer, boa mesa, moda, utilidades domésticas, viagens, carro, televisão, telefone, computador, uso de tecnologias que diminuem o trabalho manual, consumo de arte e cultura, entre outras comodidades e riquezas (p.9).

Assim, se por um lado, um conceito globalmente aceito pode facilitar análises científicas e de órgãos governamentais, por outro, corre-se o risco de acomodar a discussão sobre o tema a partir de conceitos idealistas, impostos pelo Estado. A noção de que qualidade de vida é um construto cultural (por vezes contraditório) que precisa, constantemente, ser revisado, discutido e transformado de acordo com o avanço do conhecimento e da sociedade é necessária. Assim, é importante que, por exemplo, ao se investigar os fatores relevantes na percepção de pessoas ou grupos para ser ter boa qualidade de vida, exista uma reflexão acerca das formas pelas quais esses fatores se tornaram relevantes considerando aspectos históricos, socioculturais, psíquicos, do ambiente e da inserção no mundo do trabalho.

FARQUHAR (1995) destaca que muitos estudos fazem uma abordagem superficial do tema evitando definir exatamente o que pretendem medir ou apresentam suas reais intençôes de pesquisa de forma limitada. Para o autor, qualquer estudo com méritos tem que definir claramente seu assunto e então decidir as direçôes metodológicas a seguir, principalmente por se tratar de um termo ambíguo que pode variar de pessoa para pessoa.

O desenvolvimento de uma classificação ou taxonomia de qualidade de vida é útil, não somente para demonstrar a falta de consensos, mas, também, para organizar definições existentes identificando e ordenando elementos comuns e fatores de destaque que influenciam estas definiçóes. De acordo com FARQUHAR (1995), na literatura especializada destacam-se quatro tipos de classificações. Primeiramente foram propostas definiçōes globais ou gerais, num segundo momento definiçôes que dividem o conceito em componentes ou dimensões, em terceiro lugar as definiçôes focalizadas nas quais, um dos componentes, é alvo do estudo e, por último, definições que abordam combinações das primeiras. Esses tipos de definições conforme FARQUHAR (1995) apresentam as seguintes características:

1) Definiçôes globais: são as mais comuns e apareceram mais fortemente no campo científico nas décadas de 60 e 70 . Em função de sua generalidade falam pouco sobre os componentes que as formam ou como o conceito pode ser operacionalizado, normalmente incorporam ideias de satisfação/insatisfação e de felicidade e descontentamento e por essa razão o conceito destaca-se como subjetivo e individual.

2) Definiçóes por componentes: dividem o conceito numa série de partes, componentes ou dimensões que contribuem para a qualidade de vida global, podendo ainda identificar um ou mais componentes como essencial. Essas definições são melhor operacionalizáveis e podem abranger tanto questôes objetivas (como estado de saúde e capacidade funcional, nível socioeconômico, etc) como subjetivas (julgamento pessoal sobre a satisfação com a vida, auto-estima, etc). Importante atentar que, em relação às definições por componentes, o conjunto de componentes não pode definir por excelência o global, já que, qualidade de vida potencialmente poderia ser subdividida em uma infinidade de componentes. Embora possibilitem uma melhor operacionalização, sempre haverá componentes que ficarão de fora. Os componentes de análise normalmente são escolhidos sob a ótica e interesse da área e do estudo, correndo o risco de negligenciar muitos fatores. Esse tipo de definição é muito usado na área da saúde onde um ou dois componentes são tratados para definir toda a qualidade de vida, ou unindo duas dimensóes como, por exemplo, o estado de saúde com nível socioeconômico.

3) Focalizadas em um ou mais componentes: trata-se de uma subdivisão das definições por componentes. Nestas definições um ou mais componentes são focalizados e analisados mais detalhadamente. Normalmente este tipo de definição é usado na área da saúde na qual são privilegiados certos aspectos específicos de cada quadro patológico.

4) Definições combinadas: outras definições aparecem na literatura especializada, mas não se ajustam nitidamente a nenhum tipo de abordagem. São normalmente definiçõos globais que especificam 
um ou mais componentes, tratando, por exemplo, da satisfação geral da vida, dando ênfase ao aspecto físico, mas não analisando o contexto social.

FARQUHAR (1995) salienta ainda que em muitos estudos a definição de qualidade de vida utilizada não aparece ou está subentendida, tomando alguns componentes como medida geral, prática comum na área da saúde que utiliza estados de saúde e funcional como sinônimos de qualidade de vida. $\mathrm{O}$ autor considera que, nesse caso seria melhor utilizar a expressão qualidade de vida relacionada à saúde. Além disso, um fator primário é a multidisciplinaridade no uso do conceito o que conduz a uma infinidade de definições e divergências de pensamentos mesmo dentro de uma mesma disciplina. Um problema adicional na pesquisa sobre qualidade de vida, principalmente utilizando componentes, está na dúvida do peso que se deve dar a um componente particular, que na prática, pode ter importância diferente a cada sujeito investigado.

\section{A avaliação da qualidade de vida}

Inúmeras são as formas de avaliação da qualidade de vida não havendo medidas como padrão-ouro (FARQHAR, 1995). Enquanto percepção pessoal por excelência GiLl e FeInstein (1994) defendem que muitos instrumentos poderiam ser substituídos pela simples avaliação de cada um sobre seu estado na vida, sendo que muitos instrumentos são utilizados devido a falta de clarificação conceitual do tema. Da mesma forma SEIDl e ZANNON (2004) destacam como importante a perspectiva da população a ser avaliada e não apenas a visão de um observador e, segundo as autoras, há registros de estudos e instrumentos para avaliação da qualidade de vida já na literatura médica da década de 30.

$\mathrm{O}$ Índice de Desenvolvimento Humano (IDH) é uma das formas mais tradicionais de se avaliar qualidade de vida em grandes populações. Segundo Minayo, Harts e Buss (2000) tem por objetivo ser um indicador sintético de qualidade de vida e está alicerçado na noção de capacidades, ou seja, numa leitura ampliada do conceito de desenvolvimento humano no qual, por exemplo, saúde e educação são dimensões importantes para a expansão das capacidades dos indivíduos. Assim, uma análise crítica deste indicador é sempre importante, pois este poderia estar mais relacionado com o crescimento e menos com o desenvolvimento que seria um conceito mais amplo considerando mudanças histórias da sociedade.

De acordo com relatório divulgado no ano de 2006 pelo Programa das Naçôes Unidas para o Desenvolvimento (PNUD) o Brasil melhorou o seu IDH, mas caiu uma posição no "ranking" mundial de $68^{\circ}$ para $69^{\circ}$ numa lista de 177 países e territórios. $\mathrm{O}$ estudo usa indicadores e metodologias que foram revisados e aperfeiçoados pelas fontes produtoras dos dados o que impede a comparação com anos anteriores. O Índice utilizou quatro indicadores: PIB
(Produto Interno Bruto) "per capita”, expectativa de vida, taxa de alfabetização de pessoas com 15 anos ou mais de idade e taxa de matrícula bruta nos três níveis de ensino (relação entre a população em idade escolar e o número de pessoas matriculadas no ensino fundamental, médio e superior). Os resultados indicaram que de 2003 para 2004, o Brasil avançou em duas das três dimensões do Índice de Desenvolvimento Humano (longevidade e renda) e estabilizou-se em uma (educação). A decomposição do IDH mostra que o Brasil tem um subíndice de renda superior ao da América Latina, mas inferior à média mundial. Em esperança de vida, supera a média global, mas não a latino-americana. Educação é a dimensão em que o Brasil mais se aproxima dos países ricos e mais se distancia da média mundial.

Neste ponto, a discussão a respeito do valor individual e coletivo nas análises em saúde realizada por BREIHL (2006) que, neste contexto, poderiam ser expandidas para uma questão mais geral de qualidade de vida, se faz pertinente. De acordo com o autor:

A saúde não é primordialmente 'individualsubjetiva-contingente', nem tampouco é primordialmente 'coletiva-objetiva-determinada'; ela é, sempre e simultaneamente, o movimento de gênese e reprodução possibilitado pelo concurso de processos individuais e coletivos, que se articulam e se determinam mutuamente. Ela tampouco é primeiro individual e depois coletiva, como produto da combinação de realidades individuais (p.45).

Além disso, LAURENTI (2003) discute que os instrumentos para avaliação da qualidade de vida normalmente são traduções que apresentam falhas ao serem aplicados em culturas diferentes e, por esta razão, há a necessidade de validá-los novamente sugerindo que as avaliaçôes da qualidade de vida deveriam avançar no sentido de considerar o momento histórico e o 
contexto cultural do grupo que se pretende analisar, bem como as relaçōes, influências e interdependências dos sistemas de poder presentes nos discursos.

Os instrumentos para avaliação da qualidade de vida variam de acordo com a abordagem e objetivos do estudo. Instrumentos específicos como o Medical Outcomes Study Questionaire 36-Item Short Form Health Survey (SF-36) para avaliação da qualidade de vida relacionada à saúde e do WHOQOL para avaliação da qualidade de vida geral são tentativas de padronização das medidas permitindo comparação entre estudos e culturas. Publicaçôes sobre novos instrumentos de avaliação específicos para populações ou pessoas acometidas por quadros patológicos específicos são crescentes na literatura especializada. O SF-36 é um instrumento do tipo genérico criado por Ware e Sherbourne, originalmente na língua inglesa norte-americana. No Brasil, teve sua tradução e validação cultural realizada por Ciconelu, Ferraz, Santos, Meinão e Quaresma (1999). O instrumento é constituído de 36 itens, fornecendo pontuação em oito dimensões da qualidade de vida: capacidade funcional, limitação por aspectos físicos, dor, estado geral de saúde, vitalidade, aspectos sociais, aspectos emocionais e saúde mental. A pontuação varia de 0 (pior resultado) a 100 (melhor resultado).

A necessidade da criação de medidas genéricas fez com que variáveis de muitos domínios ficassem excluídas, principalmente as mais relacionadas à cultura particular de quem se está testando devido à necessidade de comparação, sendo muitos instrumentos preconceituosos em relação a quem se pretende avaliar (Kreitler \& Kreitler, 2006). Assim, quando se propõe investigar a qualidade de vida de um grupo com indicadores como renda, transporte, salário, dor e uso de medicamentos poder-se-ia questionar se o valor destes indicadores seria o mesmo para diferentes contextos. Ao analisarmos a qualidade de vida de professores de Educação Física, por exemplo, poderíamos refletir se as dimensões importantes para estes são as mesmas dos demais educadores na escola. Além disso, segundo Kreitler e Kreitler (2006), questões como "como está sua situação agora comparada com a semana passada, ou antes, de estar doente" ou "como tal doença mudou seu estado de saúde" são opçōes para aprofundar a análise da qualidade de vida considerando uma trajetória história, por exemplo, do processo de adoecimento.

O WHOQOL foi desenvolvido pelo grupo chamado World Health Organization Quality of Life e traduzido e validado para o Brasil por um grupo de pesquisadores na Universidade Federal do Rio Grande do Sul e tem por objetivo avaliar a qualidade de vida geral das pessoas em diferentes culturas. Foram validadas duas versões do instrumento. A versão longa "WHOQOL-100" FLECK et al. (1999) considera seis domínios para análise: físico, psicológico, nível de independência, relações sociais, ambiente e aspectos espirituais/religião/ crenças pessoais. A versão curta "WHOQOL Bref" Fleck, Louzada, Xavier, Chachamovich, Vieira, SANTOS e PINZON (2000), considera quatro domínios (físico, psicológico, relaçôes sociais e meio ambiente) para análise da qualidade de vida.

Amplamente utilizado pelas diversas áreas de conhecimento o WHOQOL tem especial destaque na área da saúde considerando a necessidade de ampliação nas avaliaçõos em saúde de grupos e sociedades. O WHOQOL, de acordo com DANTAS, SAWADA e MALERBO (2003) apresenta uma vantagem de permitir a comparação de seus resultados entre diferentes populações por ser validado de forma similar para muitos países e apresentar uma abordagem multicultural. No entanto, tais comparações podem ser consideradas ingênuas no momento que vislumbramos, conforme discute CASTIEL (1994), para particularidades nos modos de perceber e responder aos estímulos considerando o contexto sociocultural. Assim, a noção de agente estressor, considerando um contexto amplo de saúde e qualidade de vida, estaria ligada, tanto a capacidade individual de lidar com determinadas situações, como pelas contingências conjunturais em que ocorrem em uma rede complexa de interligaçóes.

Desta forma parece coerente refletir sobre a necessidade de não se considerar apenas abordagens extremas na avaliação da qualidade de vida, pois, tanto um pragmatismo exacerbado, como nas abordagens puramente psicométricas, como a falta de rigor científico, não ajudam na clarificação do conceito e de suas formas de avaliação. Assim, é importante que, ao consideramos qualidade de vida como algo importante para nossa sociedade, seu conceito e suas formas de avaliação não deixem de ser discutidas e revisadas considerando o avanço histórico e as demandas individuais e da gestão pública em saúde.

Instrumentos como o SF-36 e o WHOQOL apresentam as vantagens de serem instrumentos que já tiveram sua validade e qualidades psicométricas atestadas além de permitirem a comparação com outros estudos. No entanto, esses instrumentos trazem consigo limitaçōes importantes, pois ao propor indicadores deixam de avaliar as especificidades de cada sujeito em cada contexto de avaliação. Neste 
mesmo contexto Pires, Matiello e Gonçalves (1998) fazem uma crítica ao uso das avaliações que levam em conta a distância entre o que considera patamares desejáveis e o que avalia efetivamente alcançado, pois podem ser bastante subjetivos. Podem ainda ser fortemente influenciados por mecanismos sociais de resignação e baixa expectativa causadas pela pobreza crônica, como pelo seu ambiente, isto é, pela insatisfação frente à febre de consumismo desenfreado e ascendente, marca da sociedade pós-industrial. Os autores abordam ainda que, normalmente, a escolha por diferentes indicadores de avaliação está diretamente ligada aos interesses de uso de quem estabelece, sendo que por serem tão diferentes pode até mesmo remeter a "diferentes qualidades de vida".

Em síntese, como abordam SEIDL e ZANNON (2004), grande parte dos estudos tende a adotar ou abordagens mais sociológica como a adotada pela OMS, por exemplo, com o uso do WHOQOL, ou mais específicas como as relacionada à saúde analisando os sintomas e capacidade funcional utilizando-se de inúmeros instrumentos, muitas vezes específicos para determinada patologia. Assim, a complementaridade das metodologias, ou seja, que haja a utilização de instrumentos padronizados de avaliação, que viabilizam mais facilmente a comparação com outros estudos, combinados com análises qualitativas, que permitam uma maior aproximação com a realidade a ser investigada, é uma opção a ser explorada.

Desta forma, verificamos que a análise da qualidade de vida precisa passar por aprimoramentos considerando, tanto sua dimensão operacional, como suas bases epistemológicas. É possível sugerir que conceitos como universalidade, individualidade e autonomia, bastante comuns nas avaliações de qualidade de vida, devam ser utilizados com cautela.
Além disso, se, por um lado, é necessária a complementaridade de análises mais gerais e quantitativas com abordagens focais de cunho qualitativo, por outro, é preciso ir mais longe avançando nos pressupostos de base do construto que se apresentam, em grande parte, baseados nos sistemas de produção ou então na saúde num contexto de adoecimento ou no estilo de vida pessoal.

A produção sobre qualidade de vida no Brasil de acordo com Dantas, SAWAdA e Malerbo (2003) é relativamente recente e tem aumentado a cada ano, não se restringindo a determinado grupo social, mas sendo realizada em grande parte com adultos acometidos por algum tipo de patologia, refletindo a preocupação em se conhecer de que forma essas enfermidades estão comprometendo a vida dos indivíduos focalizando as análises na qualidade de vida relacionada à saúde. Argumentamos, no entanto, que embora o estado de saúde seja bastante importante para a vida das pessoas, nem todos os aspectos da vida humana são, necessariamente, questão médica ou sanitária.

A utilização de abordagens clássicas de pesquisa de forma mais abrangente e da dialética podem contribuir para o avanço da pesquisa na área. No entanto, considerando que a percepção individual de cada sujeito é determinante para a análise da qualidade de vida e que, conforme explora PETERS (2000), a crença na pura racionalidade e na autotransparência do sujeito pode ser superada, as abordagens pós-estruturalistas, que consideram que as estruturas sócio-culturais exercem um papel importante na formação da autoconsciência, também podem abrir novos campos de pensamento considerando a investigação e o planejamento de políticas públicas em saúde e qualidade de vida.

\section{Considerações finais}

A literatura especializada aponta para a grande relevância social e científica da qualidade de vida. Apesar disso, o tema ainda apresenta muitas imprecisões conceituais e diferentes abordagens de análise podem ser úteis para a clarificação do tema. $\mathrm{O}$ fato da qualidade de vida possuir significados individuais diferentes dificulta sua avaliação e utilização em pesquisas científicas e deve ser superado considerando diferentes perspectivas de ciência. Estudos de intervenção que esclareçam possibilidades mais claras de melhoria da qualidade de vida das pessoas são escassos e necessários. 


\begin{abstract}
Quality of life: approaches, concepts and assessment

Despite the great social relevance, the theme quality of life presents theoretical/methodological inaccuracies, fact that makes difficult the investigation, the dialogue among the different areas that deal with the theme, and mainly, the application of the knowledge produced in the improvement of the population's quality of life. In order to contribute for a clarification of the concept, this study had as objective, through the reading, discussion and analysis of the specialized literature, to present the main approaches, concepts and proposals of classification and assessment of quality of life. It was verified that the approaches and conceptualizations about quality of life are presented in the literature in a varied way and, many times, divergent. The lack of theoretical consensus makes many researches to use concepts as health, well-being and life style, as synonyms for quality of life. New approaches in epistemological study of the topic are necessary as well as studies analyzing the quality of life in times of intervention are needed.
\end{abstract}

UnITERMS: Quality of life; Concept formation; Classification.

\title{
Resumen
}

Calidad de vida: abordajes, conceptos y evaluaciion

A pesar de la gran relevancia social, el tema calidad de vida presenta imprecisiones teórico/metodológicas, rasgo que dificulta la investigación, el diálogo entre las diferentes áreas que trabajan con el tema, principalmente, en la aplicación del conocimiento producido para mejorar la calidad de vida de la población. En la búsqueda para contribuir para aclarar el concepto, este estudio tuvo como objetivo, a partir de la lectura, discusión y análisis de la literatura especializada, presentar los principales abordajes, conceptos y propuestas de clasificación y evaluación de la calidad de vida. Se observó que los abordajes y conceptos sobre la calidad de vida se presentan en la literatura de forma diversificada y, por veces, divergentes. La falta de consenso teórico lleva muchas pesquisas a utilizaren conceptos como salud, bienestar y estilo de vida como sinónimos para calidad de vida. Nuevos abordajes epistemológicos en el estudio del tema son necesarios, así como estudios que investiguen la calidad de vida en situaciones de intervención.

Palabras clave: Calidad de vida; Formación de concepto; Clasificación.

\section{Referências}

BREIHL, J. Epidemiologia crítica: ciência emancipadora e interculturalidade. Rio de Janeiro: FIOCRUZ, 2006.

BUSS, P. M. Promoção da saúde e qualidade de vida. Ciência \& Saúde Coletiva, Rio de Janeiro, v.5, n.1, p.163-77, 2000. CASTIEL, L.D. O buraco e o avestruz: a singularidade do adoecer humano. Campinas: Papirus, 1994.

CICONELLI, R.M.; FERRAZ, M.B.; SANTOS, W.; MEINÃO, I.; QUARESMA, M.R. Tradução para a língua portuguesa e validação do questionário genérico de avaliação da qualidade de vida SF-36 (Brasil SF-36). Revista Brasileira de Reumatologia, São Paulo, v.39, n.3, p.143-50, 1999.

DANTAS, R.A.S; SAWADA, N.O.; MALERBO, M.B. Pesquisas sobre qualidade de vida: revisão da produção científica das universidades públicas do estado de São Paulo. Revista Latino-Americana de Enfermagem, Ribeirão Preto, v.11, n.4, p.532-8, 2003. DAY, H.; JANKEY, S.G. Lessons from the literature: toward a holistic model of quality of life. In: RENWICK, R.; BROWN, I.; NAGLER, M. (Eds.). Quality of life in health promotion and rehabilitation: conceptual approaches, issues and applications. Thousand Oaks: Sage, 1996. 
FARQUHAR, M. Definitions of quality of life: a taxonomy. Journal of Advanced Nursing, Oxford, v.22, n.3, p.502-8, 1995. FLECK, M.P.A.; LOUZADA, S.; XAVIER, M.; CHACHAMOVICH, E.; VIEIRA, G.; SANTOS, L.; PINZON, V. Aplicação da versão em português do instrumento de avaliação de qualidade de vida da Organização Mundial da Saúde (WHOQOL-100). Revista de Saúde Pública, Rio de Janeiro, v.33, n.2, p.198-205, 1999.

. Aplicação da versão em português do instrumento abreviado da qualidade de vida "WHOQOL-bref. Revista de Saúde Pública, Rio de Janeiro, v.34, n.2, p.178-83, 2000.

GILL, T.M.; FEINSTEIN, A.R. A critical appraisal of the quality of quality-of-life measurements. Journal of the American Medical Association, Chicago, v.272, n.8, p.619-26, 1994.

KREITLER, S.; KREITLER, M. M. Multidimensional quality of life: a new measure of quality of life in adults. Social Indicators Research, Prince George, v.76, n.1, p.5-33, 2006.

LAURENTI, R. A mensuração da qualidade de vida. Revista da Associação Médica Brasileira, São Paulo, v.49, n.4, p.349-66, 2003.

MICHALOS, A.C.; ZUMBO, B.D.; HUBLEY, A. Health and the quality of life: social indicators research. Social Indicators Research, Prince George, v.51, n.3, p.245-86, 2000.

MINAYO, M.C.S.; HARTZ, Z.M.A.; BUSS, P.M. Qualidade de vida e saúde: um debate necessário. Ciência \& Saúde Coletiva, Rio de Janeiro, v.5, n.1, p.7-18, 2000.

NAHAS, M.V. Atividade física, saúde e qualidade de vida: conceitos e sugestôes para um estilo de vida ativo. 3. ed. Londrina: Midiograf, 2003.

OMS. Promoción de la salud: glosario. Genebra: OMS, 1998.

PETERS, M. Pós-estruturalismo e filosofia da diferença: uma introdução. Autêntica: Belo Horizonte, 2000.

PIRES, L.P.D.E.; MATIELLO, E.M.; GONÇALVES, A. Alguns olhares sobre aplicações do conceito de qualidade de vida em educação física/ciências do esporte. Revista Brasileira de Ciências do Esporte, Campinas, v.20, n.1, p.54-7, 1998. PROGRAMA DAS NAÇÕES UNIDAS PARA O DESENVOLVIMENTO (PNUD). Índice de Desenvolvimento Humano. Brasília: PNUD, 2006. [relatório]. Disponível em: <www.pnud.org.br>. Acesso em: 9 nov. 2006.

RENWICK, R.; BROWN, I. The center for health promotion's conceptual approach to quality of fife. In: RENWICK, R.; BROWN, I.; NAGLER, M. (Eds.). Quality of life in health promotion and rehabilitation: conceptual approaches, issues and applications. Thousand Oaks: Sage, 1996. p.75-86.

SANTIN, S. Cultura corporal e qualidade de vida. Kinesis, Santa Maria, v.27, p.116-86, 2002.

SCHMIDT, S.; POWER, M.; BULLINGER, M.; NOSIKOV, A. The conceptual relationship between health indicators and quality of life: results from the cross-cultural analysis of the EUROHIS field study. Clinical Psychology \& Psychotherapy, Hoboken, v.2, n.1, p.28-49, 2005.

SEILD, E.M.F; ZANNON, C.M.L.C. Qualidade de vida e saúde: aspectos conceituais e metodológicos. Cadernos de Saúde Pública, Rio de Janeiro, v.20, n.2, p.580-8, 2004.

TANI, G. Esporte, educação e qualidade de vida. In: MOREIRA, W.W.; SIMÕES, R. (Orgs.). Esporte como fator de qualidade de vida. Piracicaba: UNIMEP, 2002. p.103-16.

WHOQOL Group. The development of the World Health Organization quality of life assessment instrument (the WHOQOL). In: ORLEY, J.; KUYKEN, W. (Eds.). Quality of life assessment: international perspectives. Heidelberg: Springer, 1994. p.41-60.

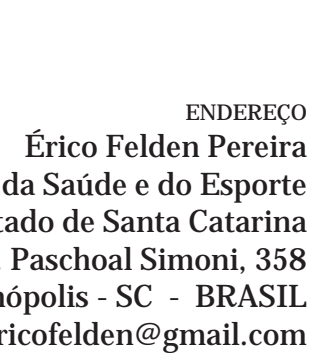

Recebido para publicação: 30/ 10/2009

Centro de Ciências da Saúde e do Esporte Universidade do Estado de Santa Catarina 1a. Revisão: 17/ 12/ 2010

2a. Revisão: 23/ 03/2012

88080-350 - Florianópolis - SC - BRASIL

Aceito: 02/ 05/2012 